\title{
High speed power generator for low power steam turbine
}

\author{
Pavel Kolpakhchyan ${ }^{1, *}$, Aleksey Shaikhiev ${ }^{1}$, Boris Lobov ${ }^{2}$, Ivan Ivanov ${ }^{3}$ and Alfred Safin ${ }^{4}$ \\ ${ }^{1}$ Rostov State Transport University, Rostov-on-Don, Russian Federation. \\ ${ }^{2}$ Platov South-Russian State Polytechnic University (NPI), Novocherkassk, Russian Federation \\ ${ }^{3}$ Russian Energy Agency, Russian Federation \\ ${ }^{4}$ Federal State Budgetary Institution of Higher Education "Kazan State Power Engineering University”, Kazan, Russian Federation
}

\begin{abstract}
The paper discusses the issues of creating a high-speed power generator for a low-power steam turbine. A $50 \mathrm{~kW}$ power generator with a rated speed of $12,000 \mathrm{rpm}$ was developed. The influence of control parameters on the power generator performance was analyzed. The electromagnetic processes in the power generator were mathematically modeled. For the single-pulse control algorithm used in the generation mode, rational ratios of the angles of the beginning and end of the voltage pulse were established. The analysis of the obtained results shows that the developed power generator meets the set requirements for joint operation with a steam turbine. The choice of a valve-inductor machine for this purpose makes it possible to significantly simplify the design, reduce the costs of production and improves the reliability of the system as a whole. The peculiarities of the implementation of control algorithms make it possible to use a minimum number of sensors and not to use the rotor position sensor.
\end{abstract}

\section{INTRODUCTION}

Autonomous and distributed power systems are one of the ways to improve the efficiency of power supply to remote facilities. They are especially relevant for energy supply of consumers of small unit capacity located at a considerable distance from each other [1-3]. In this case, the laying and operation of power transmission lines and related infrastructure require significant costs and leads to a significant increase in the cost of supplied electricity.

It is advisable to solve the problem of power supply to autonomous or remote objects using local resources, without using imported fuel. In this case, it is rational to use generating units based on low-power steam turbines. Steam for their power supply can be obtained by burning such types of fuel that cannot be used in any other way, for example, solid household waste, solid wastes of plant or animal husbandry [4-6]. In this case, in addition to electrical energy, heat energy is also generated, which can be used for technological needs and heating. If the facility is a part of a distributed energy system, its own power generation allows one to reduce the network consumption or to give it to other consumers [7]. Another promising application of power generation plants is hydrogen energy. Studies have shown that the combustion of hydrogen to obtain superheated steam with its subsequent use in a steam turbine, allows one to obtain higher energy performance of the power generation system [8].

One of the most important tasks in the development of generating units based on low-power steam turbines is the creation of a power generator (PG). At power up to
100-200 kW a turbine can efficiently operate at a high rotation speed $[4,6,9]$, so it is necessary to create a highspeed power generator capable of working together with a steam turbine without a gearbox. This paper considers the possible design of such a generator.

\section{MATERIALS AND METHODS}

A $50 \mathrm{~kW}$ power generator was developed to work together with a steam turbine as part of a complex for municipal solid waste processing [4, 5]. It powers various technological devices for the complex own needs. During waste incineration in the oxypyrolysis unit the resulting steam is saturated, with low parameters (up to $0.6 \mathrm{GPa}$ ), so to achieve the required power it is expedient to use the turbine rotation speed of $12,000 \mathrm{rpm}$ in the nominal mode. Here it is possible to use rolling bearings, which reduces the time and cost for developing and manufacturing a turbine and a PG. In prospect, for a similar turbine operating on superheated steam, it is possible to use air bearings or plain bearings to increase the rotation speed over 50,000 rpm.

The requirements of operation as part of the complex state that the PG should have a power of $50 \mathrm{~kW}$ at a speed of $12,000 \mathrm{rpm}$ in the nominal mode. To achieve the best energy performance, the turbine speed can vary from 10,000 to $14,000 \mathrm{rpm}$. In this range, the generator must produce a rated power with the possibility of a short-term increase of $15 \%$. It must remain operational up to a maximum turbine speed of $18,000 \mathrm{rpm}$. At the maximum rotation speed, the generated power must be at least $90 \%$ of the rated power in continuous operation.

Corresponding author: kolpahchyan@mail.ru 
Selection of the type and configuration of a power generator for a low-power steam turbine

The development of high-speed electric machines (HSEM) for power plants is considered in [10-12], it is shown that synchronous electric machines with permanent magnets on the rotor have the best energy performance $[10,12]$. The material of these magnets has a low tensile strength, so the HSEM rotor has a surface arrangement of magnets, which are fixed with a bandage $[10,13]$. Another feature of synchronous electric machines with permanent magnet is that excitation cannot be controlled. Therefore, the design is carried out in such a way that the EMF generated in the stator winding at the maximum speed is equal to the nominal winding voltage. To achieve the speed higher than the nominal in the constant power mode, it is necessary to use the reactive component of the electromagnetic moment. It can be achieved for a deep arrangement of permanent magnets, as exampled by traction motors of electric rolling stock [14]. For a surface arrangement of permanent magnets on the rotor, this is impossible, since there is no magnetic asymmetry along the longitudinal and transverse axes. So, to ensure constant power, it is necessary to increase the stator current. This leads to an increase in the PG mass and dimensions, a decrease in its specific indicators.

Asynchronous and synchronous reactive electric machines can be an alternative. However, asynchronous rotor of a traditional design with a short-circuited winding cannot be used due to problems with ensuring strength. In this case, electric machines with a massive rotor have found application [11,12]. Their advantages include the simplest rotor design and the ability to obtain the maximum possible rotation speeds, but in terms of their efficiency and specific indicators, they are inferior to other types of high-speed power generators [12].

In the considered case the maximum rotor speed does not exceed 20,000 rpm, the use of an asynchronous PG with a massive rotor is not justified due to high level of rotor losses and problems with its cooling. So we choose the valve-inductor electric machine (VIEM), which is of synchronous-reactive type. It doesn't have a winding on the rotor, and the stator winding is made in the form of concentrated phase windings located on the teeth. In VIEM phases are controlled independently of each other, so the number of phases can be selected in a wide range. It can generate only with one phase. To ensure operation together with a steam turbine, a PG must be able to operate in a motor mode. So, there should be minimum 3 stator phases for starting at an arbitrary position of the rotor. Analysis of various configurations of valveinductor electric machines showed that an increase in the number of stator phases leads to a decrease in the pulsations of the electromagnetic moment, better use of the material of the magnetic cores due to the reduction of the flow paths along the yoke $[15,16]$. Also, the current load on the power semiconductor devices of the power converter is reduced. Other negative consequences are an increase in magnetic losses due to an increase in the frequency of magnetization reversal of the magnetic circuit, and complication of the process of placing the stator windings. In addition, the number of winding increases, and the design of the rotor position sensor becomes more complex. Therefore, for the developed power generator we used four stator phases.

3 . Results and discussion

Taking into account the high frequency of magnetization reversal, to reduce losses, the stator and rotor magnetic circuits are made of laminated electrical steel of grade 2421 with a sheet thickness of $0.18 \mathrm{~mm}$. A scheme of the developed valve-inductor PG for a steam turbine with a capacity of $50 \mathrm{~kW}$ and a nominal speed of $12,000 \mathrm{rpm}$ is shown in Fig. 1.

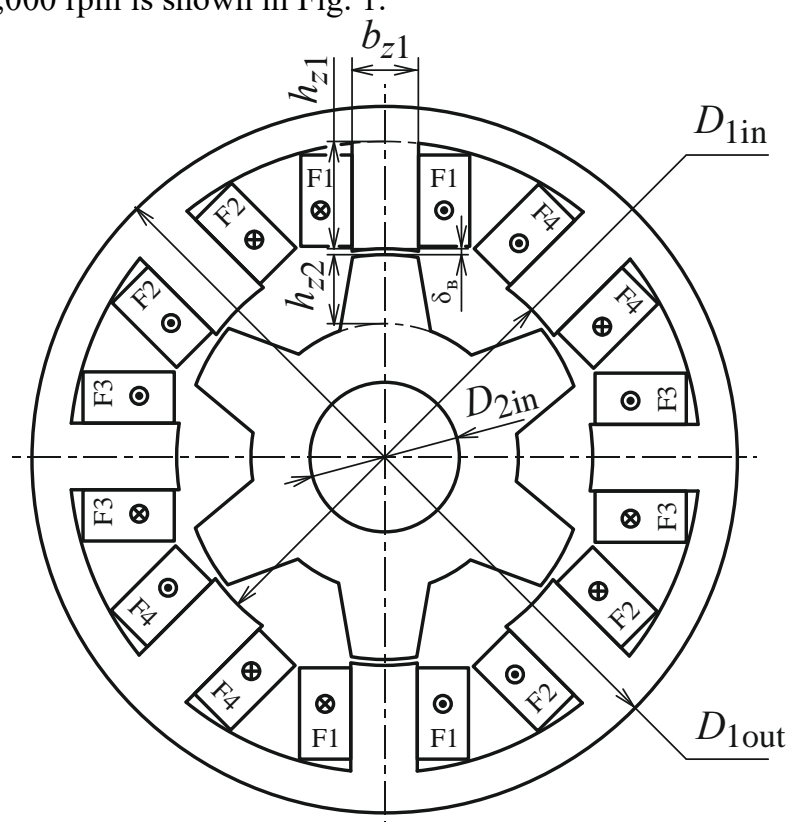

Fig. 1. A scheme of the active layer of a valve-inductor generator for a low-power steam turbine

As a result of the optimization calculations, the following main dimensions of the active part of the power generator were obtained:

- $\quad$ Number of teeth on the stator/rotor: $8 / 6$;

- $\quad$ Outer diameter of the stator: D1 out $=200 \mathrm{~mm}$;

- Inner (air gap) diameter of the stator: D1 in $=118.4$ $\mathrm{mm}$;

- $\quad$ Air gap: $\delta$ air $=0.2 \mathrm{~mm}$;

- Inner diameter of the rotor D2in $=42 \mathrm{~mm}$;

- Height of stator/rotor teeth $\mathrm{hz} 1 / \mathrm{hz} 2=30 / 20 \mathrm{~mm}$;

- Width of stator/rotor teeth bz1/bz2 $=19.0 / 19.2$ $\mathrm{mm}$;

- Length of the magnetic circuit along the air gap $1 \delta$ $=275 \mathrm{~mm}$;

- The number of turns in the stator windings: 22 ;

- Maximum stator winding current: Ifmax $=110 \mathrm{~A}$;

- Stator phase resistance $\mathrm{Rf}=0.0256 \mathrm{Ohm}$.

Each phase F1 - F4 is powered independently by unipolar current pulses and connected to an individual half-bridge autonomous voltage inverter (A1 - A4). To control the generator operation, current sensors are installed in each phase, a voltage sensor is installed in the DC link. Also, a position sensor is installed on the rotor. The information from the sensors is used by the 
micro-computer controller to determine the moments of switching on and off the power switches. The structural and functional diagram of the control system of the valve-inductor power generator is shown in Fig. 2 .

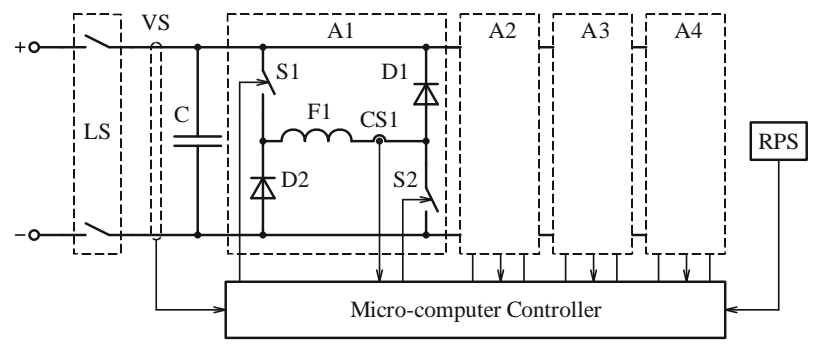

Fig. 2. Structural and functional diagram of the control system of the valve-inductor power generator: SRM - switchedreluctance motor; RPS - rotor position sensor; A1 - A4 phase modules of asymmetric half-bridge self-commutate inverter; S1, S2 - power switches (IGBT); D1, D6 - power diodes; VS - voltage sensor; CS1 - phase current sensors; LS load switcher

The VIEM phase inductance is maximum when the rotor tooth is opposite to the stator tooth (aligned position). The inductance is minimum when the rotor is in such a position that the stator tooth is between the rotor teeth (not aligned), Fig. 3. The generation period begins when the rotor passes the matched position, when the phase inductance begins to decrease. In order to begin generation, current must be in the phase by the beginning of the generation period. For this, a voltage pulse is applied to the phase with some advance. The moments of applying a voltage pulse to the phase are matched with the position of the rotor and can be represented in the form of control angles $\alpha 0$ and $\alpha 1$ (Fig. $3)$. Since the developed VIEM should basically operate in the generator mode, the not aligned position was taken as the origin of the control angles. The repetition period of voltage pulses $\left(360^{\circ}\right.$ in electrical space) corresponds to the angle of rotation of the rotor by one tooth.

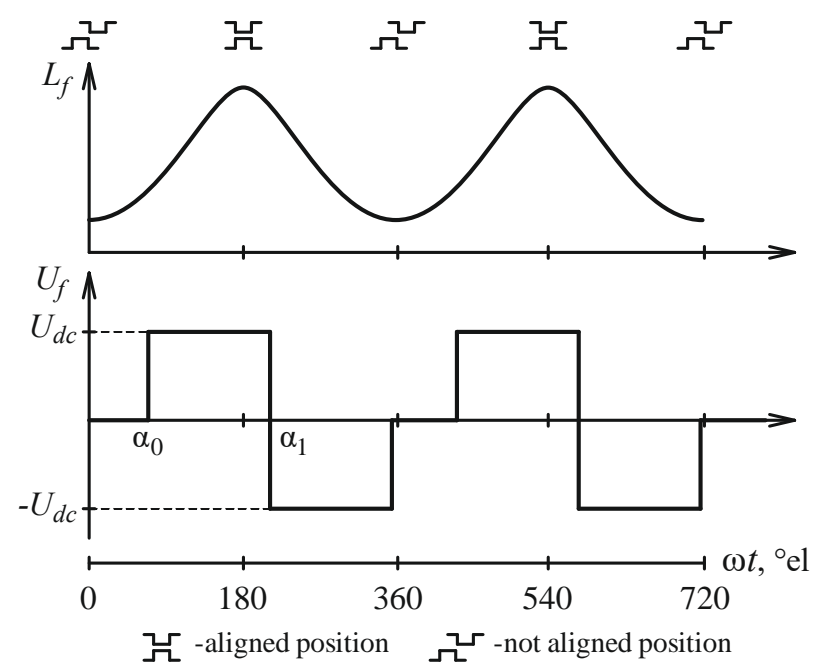

Fig. 3. Single-pulse control mode of the valve-inductor electric machine in the generator mode
The required electromagnetic moment can be obtained at various combinations of control angles, which influences current and losses in the phase windings. Determination of rational control angles is one of the most difficult tasks in the development of VIEM. We solved it by mathematical modeling of electromagnetic processes described below.

Mathematical modeling of processes in a valveinductor power generator

The phases of the valve-inductor electric machine are weakly magnetically connected to each other [16-19]. So, processes were considered only in one phase:

$$
\frac{d \Psi_{f}}{d t}=U_{f}-I_{f} \cdot R_{f},
$$

where Uf, If, $\Psi f$ are the flux linkage, voltage and phase current; $\mathrm{Rf}$ is the active phase resistance The phase current is found from:

$\Psi_{f}=f\left(I_{f}, \gamma_{r}\right)$,

where $\gamma \mathrm{r}$ is the rotation angle of the rotor relative to the stator;

The relationships of flux linkage and the phase current and rotor position (Weber-ampere phase characteristics) and phase electromagnetic moment are determined from calculating the magnetic field distribution by the finite element method, Fig.4. For the considered high-speed power generator, these calculations were performed using the FRMM software package (CDavid Meeker) [20]. The calculations were carried out at a rotor speed of 12,000 rpm, DC link voltage of $550 \mathrm{~V}$, and control angles $\alpha 0=130^{\circ} \mathrm{el}$ and $\alpha 1$ $=285^{\circ} \mathrm{el}$. Fig. 4 shows the time dependences of phase voltage and flux linkage (Uf and $\Psi f$ ), phase current (If) and electromagnetic moment (Memf). The moments of other phases are obtained by displacing the Memf dependence by the shift angle corresponding to the phase under consideration. The total electromagnetic moment is obtained by geometric addition of the dependencies of the electromagnetic moment of all phases. 

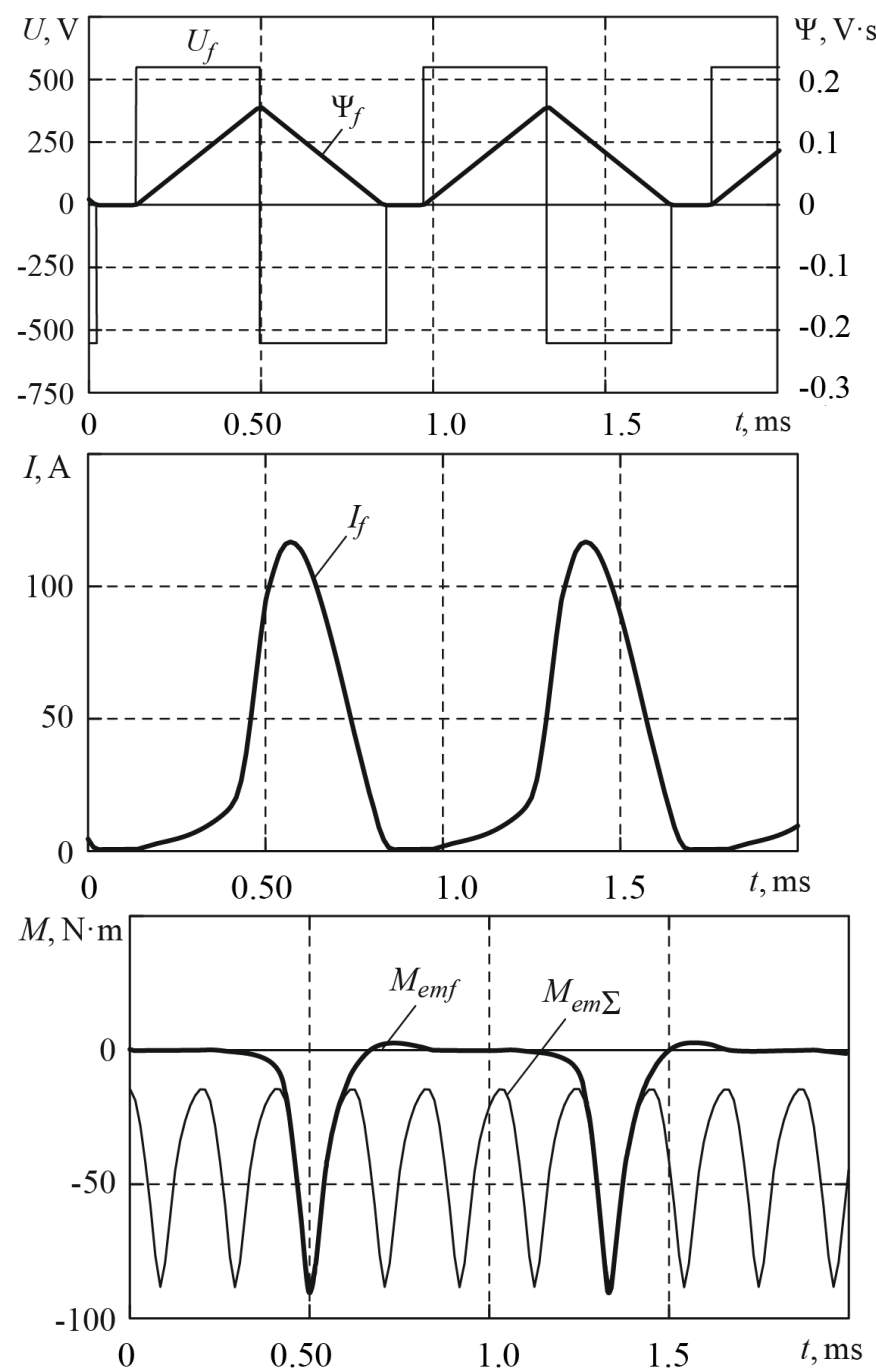

Fig. 4. Modeling electromagnetic processes in a valve-inductor power generator

These time dependences are used to calculate the average PG electromagnetic moment and the effective phase current, which are used to determine the rational values of the control angles.

The issues of control of a valve-inductor power generator

The preliminary calculations showed that in the single-pulse control generation mode, for a wide range of the pulse beginning angles, the effective phase current depends mainly on the voltage pulse width. To minimize winding losses, it is necessary to determine such a combination of control angles at which the required average electromagnetic moment would be achieved at the minimum voltage pulse width. We calculated the average angular momentum as a function of pulse beginning angle $\alpha 0$ for several pulse widths $\Delta \alpha=\alpha 1-\alpha 0$, Fig.5.

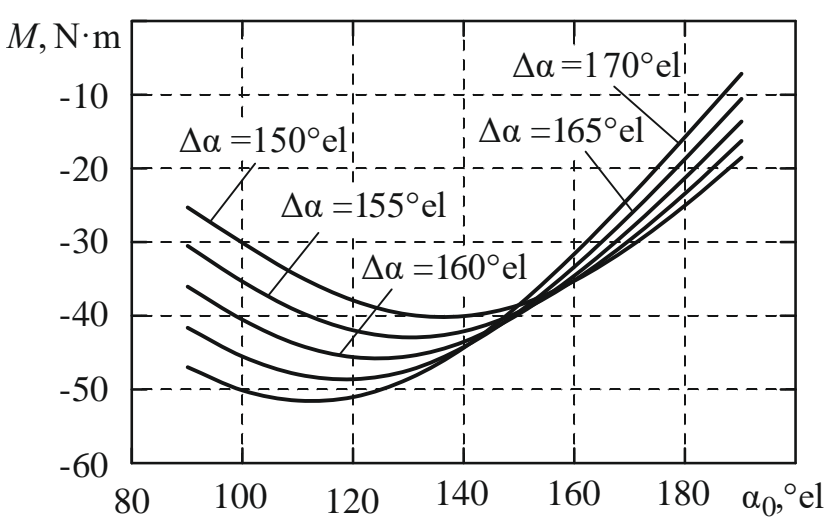

Fig. 5. Relationship between the average moment and the angle of the voltage pulse beginning $\alpha 0$ for different pulse widths

Analysis of the obtained dependences shows that they have a pronounced extremum corresponding to the minimum moment at a certain voltage pulse width. Fig. 6 shows the relationships between the angles of the beginning and the end of voltage pulse at which the minimum moment is reached.

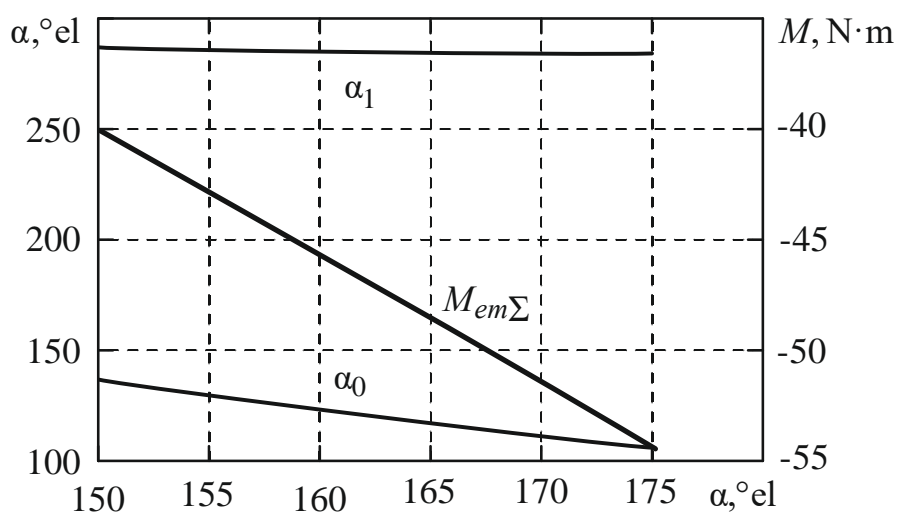

Fig. 6. Relationship between the optimal control angles $\alpha 0$ and $\alpha 1$ and the average moment and the voltage pulse width

Fig. 6 shows that the angle of voltage pulse end $\alpha 1$ practically does not change with an increase in the pulse width, and the angle of the pulse beginning $\alpha 0$ decreases linearly. The average moment also depends on the voltage pulse width linearly. This is due to the fact that the moment when the voltage pulse is turned off must be at the beginning of the generation period, which is determined only by the rotor position. The moment is determined by phase current by the time the generation began. When the moment of voltage pulse beginning shifts towards smaller angles, the phase current has time to increase. Similar results were obtained at other speeds.

So, the control system of the valve-inductor power generator can be constructed as follows. The angle of the voltage pulse end is taken constant, and the moment is controlled by changing the angle of the pulse beginning (the relationship between moment and the angle of voltage pulse supply is linear). This enables to significantly simplify the creation and configuration of 
the control system, as well as its interface with the upper-level control system.

When the rotor speed is less than the nominal, the moment control can be carried out by reducing the voltage pulse width. However, this increases the current pulse amplitude and the effective phase current resulting in an increased load on the converter power semiconductors. So, it is advisable to apply voltage modulation. The average voltage must be selected so that for equal angular momentum the pulse width is equal to that at the rated speed. With an increase in the speed above the nominal, the moment can be kept constant by increasing the voltage pulse width to the limit of $175^{\circ} \mathrm{el}$. The pause between successive pulses is sufficient for normal operation of the converter power semiconductor devices.

The peculiarities of the implementation of control algorithms make it possible to use a minimum number of sensors and not to use the rotor position sensor [19,21].

In high-speed power generator the magnetic bearings should be used instead of rolling bearings and a rotor with a smooth surface. In this case, the use of synchronous machines with permanent magnets on the rotor is justified. The development and production of a high-speed power generator and bearings with a rotation speed of more than $30,000 \mathrm{rpm}$ in a power range $30-300$ $\mathrm{kW}$ has a high cost and is not always economically justified. So valve-inductor electric machines are promising at speeds of up to $20,000 \mathrm{rpm}$ in the indicated power range.

\section{CONCLUSIONS}

The developed power generator meets the set requirements for joint operation with a steam turbine. The use of a valve-inductor machine makes it possible to significantly simplify the design, reduce the costs of production and improve the system reliability. To control a valve-inductor electric machine in the generator mode, a single-pulse mode is used. The required electromagnetic moment can be obtained at various combinations of control angles, but to minimize winding losses, it is necessary to achieve the minimum voltage pulse width. Determination of rational control angles is one of the most difficult tasks in the development of VIEM. We solved it by mathematical modeling of electromagnetic processes. The VIEM control system must preserve the angle of switching off the voltage pulse constant. The moment is controlled by changing the angle of the pulse beginning. The relationship between the moment and the angle of the voltage pulse supply is linear, that significantly simplifies the creation and configuration of the control system, as well as its interface with the upper-level control system. When the rotor speed is less than the nominal, it is advisable to regulate the moment by modulating the voltage applied to the phases. At a speed higher than the nominal, moment control is realized by changing the voltage pulse width.

\section{ACKNOWLEDGMENTS}

The research was carried out within the agreement ("Scientific and technical solutions to develop the efficient high speed generator equipment for micro gasturbine unit” № 14.604.21.0174, 26 September 2017) by order the Ministry of Education and Science of the Russian Federation, Federal Target Program "Development of the focal areas for the development the scientific and technical complex of Russia for 20142020". The unique ID for applied research (project) is RFMEFI60417X0174

\section{References}

1. F. Sioshansi, Smart Grid: Integrating Renewable, Distributed \& Efficient Energy (Academic Press, 2012).

2. E. I. Gracheva and O. V.Naumov, Estimation of power losses in electric devices of the electrotechnical complex, in 2019 International Conference on Industrial Engineering, Applications and Manufacturing, 1-6 (2019).

3. P. Kolpakhchyan, A. Shaikhiev, B. Goltsman, and A. Oshchepkov, Local intelligent energy systems based on gas microturbines with highspeed power generators, International Journal of Mechanical Engineering and Technology 9, 51-57 (2018).

4. V. Parshukov, N. Efimov, V. Papin, and R. Bezuglovz, Energy-technological complex, functioning on the basis of waste processing technologies, IOP Conference Series: Materials Science and Engineering 463, 042029 (2018).

5. V. Parshukov, A. Belov, V. Volovikov, V. Pryatkina, and V. Papin, Mathematical modeling of the waste heat boiler, part of the micro-energy complex for processing solid municipal waste, International Journal of Civil Engineering and Technology 9, 2056-2065 (2018).

6. A. V. Boicea, G. Chicco, and P. Mancarella, Optimal operation of a microturbine cluster with partial-load efficiency and emission characterization, in PowerTech, 2009 IEEE Bucharest, 1-8 (2009).

7. E. Gracheva and A. Alimova, Calculation methods and comparative analysis of losses of active and electric energy in low voltage devices, in 2019 International Ural Conference on Electrical Power Engineering (UralCon), 361-367 (2019).

8. R. Aminov and A. Egorov, Assessment of technical and economic efficiency of a closed hydrogen cycle at npp, International Journal of Hydrogen Energy 45, 15744 - 15751 (2020).

9. T. Giampaolo, Gas Turbine Handbook: Principles and Practice, Fifth Edition, 5th ed. (Fairmont Press; 5 edition (November 15, 2013), (2013).

10. D. Gerada, A. Mebarki, N. L. Brown, C. Gerada, A. Cavagnino, and A. Boglietti, High-speed electrical machines: Technologies, trends, and developments, 
IEEE Transactions on Industrial Electronics 61, 2946-2959 (2014).

11. P. Kolpakhchyan, V. Parshukov, A. Shaikhiev, A. Kochin, and M. Podbereznaya, High speed generator for gas microturbine installations, International Journal of Applied Engineering Research 12, 13874-13878 (2017).

12. D. T. McGuiness, M. O. Gulbahce, and D. A. Kocabas, A performance comparison of different rotor types for high-speed induction motors, in 2015 9th International Conference on Electrical and Electronics Engineering, 584-589 (2015).

13. P. G. Kolpakhchyan, B. N. Lobov, A. P. Mikitinskiy, and I. V. Rusakevich, The production possibility of permanent magnet high speed power generator rotors, 2018 10th International Conference on Electrical Power Drive Systems, 2018 - Conference Proceedings (2018)

14. M. Kondo, J. Kawamura, and N. Terauchi, Performance comparison between a permanent magnet synchronous motor and an induction motor as a traction motor for high speed train, IEEJ Transactions on Industry Applications 126, 168-173 (2006).

15. M. M. Bouiabady, A. D. Aliabad, and E. Amiri, Switched reluctance motor topologies: A comprehensive review, in Switched Reluctance Motor, edited by A. Tahour and A. G. Aissaoui (IntechOpen, Rijeka, 2017) Chap. 1.

16. D. Torrey, Switched reluctance generators and their control, IEEE Transactions on Industrial Electronics 49, 3-14 (2002).

17. V. Do and M. C. Ta, Modeling, simulation and control of reluctance motor drives for high speed operation, in 2009 IEEE Energy Conversion Congress and Exposition (IEEE, 2009), 1-6 (2009).

18. D. Susitra, A. Jebaseeli, and S. Paramasivam, Switched reluctance generator - modeling, design, simulation, analysis and control a comprehensive review, International Journal of Computer Applications 1, 12-25 (2010).

19. P. Kolpakhchyan, A. Shaikhiev, and A. Kochin, Sensorless control of the high-speed switchedreluctance generator for the steam turbine, Advances in Intelligent Systems and Computing 680, 349-358 (2018).

20. D. Meeker, Finite Element Method Magnetics. Version 4.2. Users Manual (2018).

21. P. Kolpakhchyan, V. Parshukov, B. Lobov, N. Efimov, and V. Kopitza, The rotor initial position determination of the hi-speed switchreluctance electrical generator for the steam-microturbine, Lecture Notes in Electrical Engineering 554, 628638 (2020). 